\title{
ESTRATÉGIAS INTERACIONAIS USADAS POR ESTUDANTES UNIVERSITÁRIOS DE ITALIANO LE DE NIVEIS INICIAL E AVANÇADO DURANTE CONVERSAÇÕES SIMÉTRICAS
}

\author{
INTERACTIONAL STRATEGIES USED BY UNIVERSITY STUDENTS \\ OF ITALIAN AS A FOREIGN LANGUAGE (IFL) AT BASIC OR \\ ADVANCED LEVELS DURING SYMMETRIC CONVERSATIONS
}

\section{Roberta Ferroni*}

\section{RESUMO}

O presente artigo analisa, à luz dos estudos conversacionais, o desenvolvimento da competência interacional, com especial atenção aos marcadores discursivos e às interrupções, em aprendizes de italiano LE, durante conversações semi-guiadas. O estudo foi realizado entre estudantes universitários de italiano como Língua Estrangeira, inscritos no primeiro e último ano do curso de Letras Italiano da Universidade de São Paulo, no Brasil. A presença maciça dos sinais interacionais para concordar, usados pelo falante e pelo interlocutor, associada a um uso esporádico de interrupções competitivas e de marcadores discursivos metatextuais, indicam que os estudantes, inclusive os de nível avançado, são pouco propensos à cultura da discussão. Apesar das repetidas dificuldades no gerenciamento da comunicação, expressas por hesitações, construções verticais e pedidos de ajuda, os participantes não hesitam na tarefa atribuída e fazem o melhor para manter a conversa viva. A variedade dos marcadores discursivos presentes na interlíngua é bastante semelhante nos dois níveis, com exceção dos marcadores de concordância, os quais são mais variados no nível avançado e dos fatismos, usados exclusivamente no nível inicial. Esse dado nos faz supor que a um nível de competência mais elevado não necessariamente corresponde uma gama mais vasta de marcadores discursivos. É provável que outros fatores tenham influenciado na interlíngua dos estudantes, como o tipo de insumo e as atividades realizadas em classe visando à observação de determinadas formas. No que tange ao nível didático, emerge a necessidade de utilizar, desde os níveis iniciais, oportunas atividades de observação e de produção, que permitam a tomada de consciência sobre os mecanismos conversacionais que regulam as discussões entre nativos.

Palavras-chave: competência interacional; estudantes de italiano LE; marcadores discursivos, interrupções.

\section{ABSTRACT}

This paper discusses the development of interactional competence in the light of conversational studies. More specifically, the focus will be on the use of discourse markers

\footnotetext{
* Universidade de São Paulo, USP, São Paulo, SP, Brasil. robertaferronibr@gmail.com
} 
in semi-guided conversations with learners of Italian as a foreign language (FL). The study has been carried out with university students enrolled in the first and last year of the Undergraduate Course in Italian at the University of São Paulo in Brazil. The heavy presence of agreement discourse markers combined with the sporadic use of competitive interruptions and metatextual discourse markers indicate that the students are not predisposed to a culture of discussion. This result was found both at beginner and advanced levels. Despite some difficulties in managing communication, expressed through hesitation, vertical constructions and requests for help, the informants do not withdraw from the task at hand and do everything they can to maintain the conversation flow. The variety of discourse markers in learners' interlanguage is essentially the same at both levels, except for agreement discourse markers, which are more varied at the advanced level, and phatic expressions, which are used exclusively at the beginner level. These data lead us to assume that higher levels of competence do not necessarily result in the use of a wider range of discourse markers. Other factors are likely to have influenced learners' interlanguage, such as the type of input learners were exposed to, as well as their engagement in tasks which required them to notice specific language forms. From a pedagogical point of view, it emerges that suitable observation and production activities should be used from the beginner levels, as these tasks help raising learners' consciousness about those conversational mechanisms which regulate discussions among native speakers.

Keywords: interactional competence; learners of Italian as a FL; discourse markers; interruptions.

\section{INTRODUÇÃO E OBJETIVO DO ESTUDO}

A competência interacional (KRAMSCH, 1986; YOUNG, 2011; PEKAREK DOEHLER ${ }_{i}$ POCHON-BERGER, 2015) revela o grau de participação na interação em curso através de: marcadores de atenção, solicitações de esclarecimentos e, ainda, capacidade de tomar a fala e gerenciar as trocas de turno, interrupções e atividades de auto e hétero reparação, prolongamento do som, pausas lexicalizadas e não lexicalizadas e marcadores discursivos, utilizados tanto por parte do falante quanto pelo interlocutor.

Nos últimos anos, com o objetivo de descrever a competência interacional dos estudantes de italiano como segunda língua (doravante L2) e língua estrangeira (doravante LE) e de identificar eventuais sequências aquisicionais dos marcadores discursivos (doravante MD), intensificou-se uma série de pesquisas que analisam, à luz de diversas perspectivas, a macro classe dos MD como um todo e seu uso. ${ }^{1}$

Partindo do pressuposto de que, para fins de estudo da competência interacional em LE, cada contexto deve ser considerado "único", dado que os resultados dependem de uma série de variáveis contextuais, o objetivo principal da

1. Para um panorama abrangente a respeito do estudo específico dos MD presentes na interlíngua dos estudantes de italiano L2 e LE, sugerimos o estudo realizado por Nuzzo e Santoro (2017). 
presente contribuição é examinar as estratégias interacionais utilizadas no decorrer de conversações simétricas por um grupo de estudantes universitários de italiano LE, falantes nativos de português brasileiro e inscritos no primeiro e último anos do Curso de Letras em Italiano da Universidade de São Paulo, no Brasil ${ }^{2}$.

Essa investigação, que se coloca entre os estudos de ensino de língua e a pesquisa interacionista, será conduzida a partir da abordagem conversacional (SACKS; SCHEGLOFF; JEFFERSON, 1974; BAZZANELLA, 1994) que nos permitirá:

- revelar se e quais MD são utilizados, com a finalidade de gerenciar uma interação semi-guiada;

- identificar possíveis semelhanças e divergências, relativas ao uso dos MD, entre estudantes de italiano LE de nível inicial e avançado;

- identificar as estratégias interacionais utilizadas, objetivando a construção conjunta de uma interação simétrica;

- extrair informações sobre plano didático que possam ser úteis para a elaboração de materiais específicos com a finalidade de desenvolver a competência interacional em italiano LE;

O presente artigo é estruturado da seguinte maneira: na seção 2 delineia-se um referencial teórico a respeito das pesquisas desenvolvidas sobre MD em italiano LE e L2; na seção 3 descreve-se o aparato teórico utilizado como base para o estudo; nas seções 4 e 5 introduzem-se o contexto dentro do qual foi desenvolvida a pesquisa e a sua metodologia; na seção 6 propõe-se a análise dos dados recolhidos e, por fim, passa-se à discussão e às conclusões (seções 6 e 7).

\section{AS PESQUISAS SOBRE OS MARCADORSE DISCURSIVOS NA INTERLÍNGUA DOS ESTUDANTES DE ITALIANO L2 E LE}

Entre os trabalhos mais significativos já desenvolvidos sobre a aprendizagem dos MD encontramos os do grupo A.Ma.Dis. Surgido no interior do Departamento de Filologia Italiana da Universidad Complutense de Madrid, consiste em um dos maiores grupos de pesquisa especializado no estudo do processo de aprendizagem das estratégias de co-construção conversacional de estudantes de italiano LE (BINI, PERNAS, 2008; GUIL ET AL., 2008; BORREGUERO; PERNAS, 2009; GUIL; PERNAS; BORREGUERO，2010; PERNAS; GILLANI; CACCHIONE，2011;

2. O estudo é financiado pela agência de fomento FAPESP (2016/08917-9). 
GUIL, 2015). O corpus de referência do grupo é composto por 40 conversações simétricas e assimétricas, entre alunos espanhóis de nível iniciante, intermediário e avançado, correspondentes aos níveis A1, B1 e B2 do Quadro Comum Europeu de Referência para as Línguas (doravante QCER, 2002), inscritos no curso de italiano LE da Escuela Oficial de Idiomas (Espanha). Aos participantes da pesquisa foi solicitado realizar, na frente de uma câmera, situações de comunicação que posteriormente foram transcritas e analisadas à luz da pragmática (BRAVO, 2004) e da análise conversacional (SACKS; SCHEGLOFF; JEFFERSON, 1974). Os dados evidenciam que, independentemente do nível de competência linguística possuído, os estudantes utilizam uma profusão de estratégias e de modalidades de cooperação, diferentes com relação à língua em estudo, além de se manifestarem por meio do recurso de "construções verticais" (GUIL ET AL., 2008, p. 722)³ do discurso, sugestões lexicais, back-channels, hétero correções, interrupções e sobreposições - iniciadas pelo interlocutor - com a intenção de manter viva a conversação. As interrupções não constituem para os falantes uma ameaça à imagem do interlocutor (SACKS, SCHEGLOFF; JEFFERSON, 1974), mas são interpretadas como "contribuição ao sucesso da interação (...) uma vez que representam uma estimulante substituição no esforço comunicativo de levar adiante a tarefa" (PERNAS; GILLANI; CACCHIONE, 2011, p. 72, tradução nossa) ${ }^{4}$. Com relação ao emprego dos MD, foi observada uma "polifuncionalidade exasperada dos elementos adquiridos, mais ampla e claramente discrepante no que diz respeito à L2" (PERNAS; GILLANI; CACCHIONE, 2011, p. 72, tradução nossa) $)^{5}$. Com efeito, nos níveis iniciais, os estudantes são levados a empregar um escasso número de MD aos quais vem atribuído um alto número de funções, que não necessariamente coincidem com aquelas da língua objeto de estudo. Os marcadores mais frequentemente utilizados para tomada de turno são: sì, no, e, perché, seguidos por ok, d’accordo, ma, allora, però, non so, cioè, va bene. É abundante, além disso, a quantidade de pausas, hesitações e prolongamentos sonoros que atestam uma certa dificuldade de planejamento do discurso. Surpreende, ainda, a quase total ausência de reformulações como voglio dire, per esempio, cioè, as quais, especialmente nos níveis iniciais, poderiam ser de grande ajuda, considerando-se que servem para ganhar tempo e organizar a própria fala (GUIL, 2015, p. 376). Um outro dado que emerge consiste no uso de certos MD

3. Costruzioni verticali (GUIL ET AL., 2008, p. 722).

4. Contributo al successo dell'interazione (...) giacché rappresentano una risollevante sostituizione

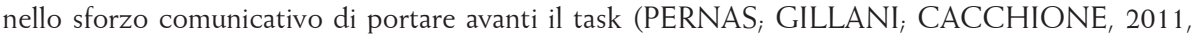
p. 72).

5. Polifunzionalità esasperata degli elementi acquisiti, più ampia e palesemente discrepante rispetto alla L2 (PERNAS, GILLANI; CACCHIONE, 2011, p. 72). 
influenciado pela semelhança fônico-funcional com a língua materna (doravante LM) dos estudantes (PERNAS, GILLANI; CACCHIONE, 2011, p. 74).

Os resultados que surgiram dessas pesquisas estimularam uma reflexão sobre o plano didático, chamando a atenção para a necessidade de oferecer em sala de aula maiores oportunidades de favorecer uma pedagogia atenta ao desenvolvimento da competência discursiva em italiano LE e L2, mediante: a exposição a um insumo adequado e autêntico, composto em sua maioria por conversações cotidianas, assim como o uso de atividades didáticas significativas e envolventes (PERNAS, GILLANI; CACCHIONE, 2011) que favoreçam a interação em vez da fala individual (WALSH, 2016, p. 62).

Conclusões análogas às descritas acima foram apresentadas por Ceković (2014) que estuda um corpus de produções orais, recolhido entre estudantes universitários sérvios, participantes dos estudos de italianística, compreendendo os níveis entre A2 e C1 do QCER (2002). Os alunos, no decorrer de uma entrevista, tiveram que responder a perguntas pessoais conduzidas por um examinador $\left(1^{\circ}\right.$ ano $)$, descrever um livro ou uma imagem $\left(2^{\circ}\right.$ ano), descrever a vida na própria cidade $\left(3^{\circ}\right.$ ano), simular uma entrevista de trabalho ( $4^{\circ}$ ano). Nesses casos, a produção oral dos alunos também se caracteriza por uma notável presença de pausas cheias de eeh, ebm, difundidas entre todos os estudantes e nos quatro grupos. Diferentemente do corpus A.Ma.Dis, a partir do $3^{\circ}$ ano, surgem indicadores de reformulação cioè, insomma, quindi e há um abuso funcional de non lo so, usado como indicador de exemplificação a partir do $2^{\circ}$ ano. Igualmente significativos são os marcadores relativos à concordância e/ ou à recepção por parte do interlocutor. À medida que a competência aumenta, há uma multiplicação das formas dos MD e um alargamento de suas funções.

A pesquisa realizada por Jafrancesco (2015) estuda, em termos de aquisição, o uso dos MD nos vários níveis de competência linguístico-comunicativa em um corpus de interação face a face, com tomada de turno parcialmente livre sobre um tema de estudo escolhido pelo participante. A tipologia de alunos examinados é constituída por 20 estudantes universitários, dentre os quais 11 são espanhóis e 9 alemães, em mobilidade internacional, e que têm desenvolvido as próprias competências linguísticas em contexto espontâneo e guiado. A pesquisa permitiu evidenciar sequências específicas de aquisição dos $M D$, com base no nível de competência linguístico-comunicativa do participante. No que diz respeito à gestão dos MD nos vários níveis, nota-se a predominância tanto dos MD interacionais por parte do falante em relação aos $\mathrm{MD}$ usados pelo interlocutor, como dos $\mathrm{MD}$ metatextuais. Esse dado é determinado pelo tipo de tarefa atribuída. No caso em questão, os participantes deviam dirigir-se ao entrevistador, que limitava as 
próprias intervenções ao mínimo possível. Com o avanço da competência, os preenchedores de pausas - que prevalecem sobre os outros MD e são realizados por pausas cheias, como $a b m, e h, m b$ - diminuem e as interjeições vêm substituídas pelas reformulações praticamente, niente, non so. Esse dado não coincide com o que foi evidenciado pelo grupo A.Ma.Dis, no qual, inclusive nos níveis mais avançados, aponta-se uma quase total ausência de reformulações. Como já exposto pelo grupo espanhol, nas variedades interlinguísticas mais avançadas os MD interacionais e metatextuais desenvolvem uma gama de funções mais ampla em comparação com o nível básico. Entre as microfunções majoritariamente representadas pelos MD interacionais figuram: preenchedores de pausas, tomada de turno, mecanismos de modulação, cessão de turno, assunção/pedido de concordância e/ou confirmação metalinguística. Entre os MD interacionais usados pelo interlocutor aparecem: concordância/confirmação/reforço. As funções mais frequentes realizadas pelos MD metatextuais são: demarcativas, indicadores de reformulação, focalizadores.

O emprego dos MD é analisado, por uma perspectiva do ensino de línguas, no estudo de Ferroni e Birello (2015), que indaga os MD utilizados durante o desenvolvimento de tarefas em pequenos grupos e destinadas a promover a interação entre estudantes de italiano como LE, falantes nativos de português brasileiro e catalão/espanhol. Confrontando os dois corpora, emerge que os dois grupos de participantes se comportam de modo análogo, utilizando por vezes MD na LM. A categoria dos sinais interativos mais frequente é a dos fatismos e dos mecanismos de aprovação, enquanto que os marcadores metatextuais estão totalmente ausentes. Quando os MD são expressos na LM, geralmente falta atividade de negociação, porque predomina nos falantes o desejo de concluir a tarefa proposta. Em uma contribuição sucessiva, Ferroni e Birello (2016) estudam como são tratados os MD no livro didático de italiano LE Bravissimo! 3 (BIRELLO e VILAGRASA, 2014), que segue uma abordagem orientada à ação. A partir da análise das propostas didáticas, percebe-se que a reflexão sobre esses elementos linguísticos é ligada a propostas de atividades interativas significativas, nas quais o estudante possui um objetivo específico para cumprir e que oferecem oportunidades de reutilizar os MD análogas àquelas que existem fora da sala de aula.

Os estudos aquisicionais e de didática de línguas citados até aqui examinam contextos muito diferentes entre si, todavia é possível destacar um consenso geral entre os autores no que concerne ao papel desempenhado pelos MD. Com efeito, sua presença na interlíngua representa um claro sinal a ser relacionado ao desenvolvimento da competência interacional, considerando-se que desenvolvem um papel determinante aos objetivos da co-construção do discurso e do sentido. 
Nas variedades pré-básicas, a interlíngua dos estudantes é caracterizada, em decorrência da tomada de turno, por pausas cheias, hesitações e prolongamentos vocálicos, que atestam uma certa dificuldade por parte do falante em organizar o próprio discurso, além de um pequeno uso dos $\mathrm{MD}$, aos quais são atribuídas funções que nem sempre coincidem com as originais. À medida que a competência avança, o repertório linguístico dos estudantes é preenchido por uma ampla variedade de MD que se aperfeiçoam sempre mais e ajudam os interagentes a gerenciar os turnos e a regular a fala. Além disso, a literatura sobre o assunto sugere que os resultados devem ser sempre considerados parcialmente, posto que são sujeitos a uma grande variabilidade sociolinguística.

De fato, a presença ou ausência de um determinado elemento discursivo está estritamente conectada a variáveis que são difíceis de verificar, como, por exemplo, a modalidade adotada para coletar dados, o tipo de tarefa comunicativa à qual os interagentes são submetidos, as preferências pessoais e o repertório linguístico de cada falante, o tipo de insumo a que estão expostos e a abordagem de ensino utilizada na sala de aula.

\section{OS MARCADORES DISCURSIVOS E AS INTERRUPÇÕES}

A conversação face a face é fruto de uma colaboração, de um processo contínuo de negociação, que pressupõe um envolvimento ativo dos diversos participantes da interação para alcançar a construção da mensagem. Como já antecipamos no parágrafo 1, os $\mathrm{MD}$, aqui entendidos como elementos que "esvaziando-se em parte de seu sentido originário, adquirem valores acrescidos e servem para destacar a estruturação do discurso, conectar elementos frasais, interfrasais, extrafrasais e explicitar a colocação do enunciado em uma dimensão interpessoal, salientando a estrutura interativa da conversação" (BAZZANELLA, 2006, p. 455, tradução nossa $)^{6}$, desenvolvem um papel determinante aos objetivos da coesão interacional, uma vez que "além do seu significado literal, transmitem outros valores dependentes do contexto, que sublinham a interação em curso e o desenvolvimento da própria conversação" (BAZZANELLA, 1994, p. 150) ${ }^{7}$.

6. Svuotandosi in parte del loro significato originario, assumono dei valori aggiuntivi che servono a sottolineare la strutturazione del discorso, a connettere elementi frasali, interfrasali, extrafrasali ed a esplicitare la collocazione dell'enunciato in una dimensione interpersonale, sottolineando la struttura interattiva della conversazione (BAZZANELLA, 2006, p. 455).

7. Oltre al loro significato letterale, veicolano altri valori dipendenti dal contesto, che sottolineano l'interazione in corso e lo sviluppo stesso della conversazione (BAZZANELLA, 1994, p. 150). 
Dado que um dos objetivos do estudo é examinar as estratégias interacionais utilizadas no decurso de conversações simétricas, entre alunos de italiano LE de nível inicial e avançado, a pesquisa será conduzida à luz de estudos conversacionais. (SACKS; SCHEGLOFF; JEFFERSON, 1974). Para localizar as funções dos MD, fazemos referência à taxonomia da matriz conversacional desenvolvida por Bazzanella (1995). A estudiosa agrupa os MD em duas subcategorias (BAZZANELLA, 1994):

- Os MD interacionais produzidos pelo falante, ou seja, aquele que profere determinado enunciado em um dado momento; aqueles produzidos pelo interlocutor, isto é, por alguém que participa da troca comunicativa sem estar de posse da troca nesse momento específico (e portanto participa em silêncio ou por meio de sinais não verbais ou de MD específicos). Estes compreendem os MD usados pelo falante para tomar o turno, chamar a atenção, solicitar acordo ou a confirmação do interlocutor, os fatismos e os mecanismos de modulação, assim como os $\mathrm{MD}$ usados por parte do interlocutor para interromper, confirmar a atenção, demonstrar concordância, assinalar a recepão.

- Os MD metatextuais servem para organizar o texto do ponto de vista da articulação e da estrutura argumentativa e compreendem os demarcativos, os focalizadores e os indicadores de reformulação.

As tabelas 1 e 2 indicam as funções dos MD para cada macrocategoria, acompanhadas de alguns exemplos.

Tabela 1. Funções interacionais dos marcadores discursivos

\begin{tabular}{|l|l|}
\hline Por parte do falante & Por parte do interlocutor \\
\hline $\begin{array}{l}\text { Sinais relativos à tomada de turno: ex. allora, ecco, } \\
\text { ma, e }\end{array}$ & Mecanismos de interrupção: ex. allora, scusa, ma \\
\hline Chamada de atenção: ex. senti, dimmi, mi segui? & Confirmação de atenção: ex. davvero, mb \\
\hline $\begin{array}{l}\text { Sinais relativos à concordância: ex. no? ti pare? dico } \\
\text { male? }\end{array}$ & $\begin{array}{l}\text { Confirmação de concordância: ex. perfetto, } \\
\text { assolutamente, come no }\end{array}$ \\
\hline Controle da recepção: ex. eb? capisci? capito? & Fatismos: ex. lo credo, so bene, povero \\
\hline Fatismos: ex. come sai, sai, capisci & Back-channels: ex. esatto, davvero, mb \\
\hline $\begin{array}{l}\text { Mecanismos de modulação: ex. naturalmente, } \\
\text { magari, se non mi sbaglio }\end{array}$ & \\
\hline
\end{tabular}


Tabela 2. Funções metatextuais dos marcadores discursivos

\begin{tabular}{|l|l|}
\hline Demarcativos: & Poi, così, però, allora, quindi, perché \\
$\begin{array}{l}\text { organizam o texto do ponto de vista da } \\
\text { articulação e da estrutura argumentativa. }\end{array}$ & Però, invece \\
\hline $\begin{array}{l}\text { Focalizadores: } \\
\begin{array}{l}\text { usados pelos falantes para assinalar os pontos } \\
\text { centrais do discurso e podem endereçar e regular } \\
\text { a elaboração da informação em nível cognitivo }\end{array}\end{array}$ \\
\hline $\begin{array}{l}\text { Indicadores de reformulação: } \\
\begin{array}{l}\text { consistem em paráfrases, correções e } \\
\text { exemplificações }\end{array}\end{array}$ \\
\hline
\end{tabular}

Além dos MD, as interrupções também são tomadas em análise. Com efeito, a conversação simétrica é caracterizada por um complexo trabalho de coordenação e de sincronização, para que os falantes possam alternar os próprios turnos de modo ordenado. Todavia, a sucessão dos turnos não é regular, como ocorre, pelo contrário, em certos tipos de conversações assimétricas (ORLETTI, 2000), mas é intercalada por sobreposições, partidas simultâneas e interrupções (BAZZANELLA, 1994, p. 175). Segundo a classificação proposta por Bazzanella (1994) e adotada por nós, são três as variáveis que incidem sobre o tipo de interrupção, quais sejam:

- o discurso simultâneo que permite classificar as mudanças de turno em "suaves e não suaves" ${ }^{\prime \prime}$;

- a conclusão do enunciado por parte do primeiro falante;

- a obtenção da mudança de turno por parte de quem interrompe.

Outra distinção importante introduzida pela estudiosa é representada pelas interrupções suportivas e competitivas (BAZZANELLA, 1994, pp. 188-189). Com as interrupções suportivas, o interlocutor não visa a tomar o turno, mas a sustentar o falante de turno. São exemplos de interrupções suportivas as realizadas por meio de back-channels e de sugestões lexicais. Por outro lado, as interrupções competitivas, que compreendem a interrupção simples, a sobreposição e a interrupção vã, constituem uma estratégia que ameaça a face negativa do falante, dado que implicam a não aceitação do outro como falante (HAVERKATE, 1994).

8. Morbidi e non morbidi. 


\section{DESCRIÇÃO DO CONTEXTO DE PESQUISA}

No momento da coleta de dados, os nossos participantes estavam inscritos respectivamente no $1^{\circ}$ e $5^{\circ}$ ano do Curso de Letras em Português e Italiano da Faculdade de Filosofia, Letras e Ciências Humanas da Universidade de São Paulo. Trata-se de oito estudantes que chamaremos por nomes fictícios: Flavio, Gabriele, Fernanda, Giulia, Talita, Pedro, Maia e Carol ${ }^{9}$. O curso de Letras em Italiano, com a duração de cinco anos, propõe disciplinas de literatura, cultura e língua italiana, que partem do nível A1 e vão até o nível B1 do QCER (2002) ${ }^{10}$. Cada disciplina tem duração semestral e a carga horária total oscila entre um máximo de 60 a um mínimo de 30 horas por semestre.

No momento da pesquisa, o grupo composto por Flavio, Gabriele, Fernanda e Giulia, que, por razões de clareza expositiva, chamaremos nível inicial, havia recentemente concluído o nível II de língua italiana, correspondente ao nível A2 do QCER (2002). O grupo de Tania, Pedro, Maia e Carol, que denominaremos avançado, havia concluído o último nível da língua, correspondente ao nível B1 do QCER (2002). Podemos afirmar que o perfil dos estudantes é homogêneo no que tange à idade, estudos, experiências precedentes e conhecimentos linguísticos: têm idade entre 22 e 33 anos; com exceção de Tania, nunca estiveram na Itália e possuem contato com o italiano exclusivamente na universidade. Tania é a única que esteve duas vezes na Itália por motivos de turismo e, além disso, possui um certificado de italiano como LE correspondente ao nível C1 do QCER (2002). Entre as línguas que constituem o repertório linguístico dos participantes temos: italiano e inglês, que são comuns a todos, alguns declaram conhecer também espanhol, francês e japonês. Apesar de terem realizado o mesmo percurso de estudo, as competências linguístico-comunicativas se diferenciam de modo notável de estudante para estudante, como nos casos, por exemplo, de Gabriele, Pedro e Tania, que se expressam com maior facilidade com relação aos colegas. Esse dado constitui uma característica central do contexto analisado. Com efeito, é comum que toda turma de alunos seja caracterizada por uma grande diversidade em termos de competência entre os estudantes.

Os cursos de italiano são ministrados por docentes do Departamento de Letras Modernas da Universidade de São Paulo. Sete dos professores possuem o português brasileiro como LM, três possuem LM italiana. Embora se baseiem em

9. Antes de iniciar a pesquisa, solicitamos que cada estudante preenchesse um questionário sociolinguístico.

10. As disciplinas de língua são no total sete, quais sejam: Língua I, II, III, IV, V, VI e VII. 
programas referenciais comuns, cada professor é livre para escolher e criar o próprio material didático, com base nas próprias convicções pedagógicas. Os alunos do $1^{\mathrm{o}}$ ano participaram, por dois semestres consecutivos, do curso de Língua italiana I e de Língua Italiana II, ministrado pela professora-pesquisadora ${ }^{11}$. O material didático utilizado em classe é proveniente dos livros Bravissimo! 1-A1 (BIRELLO; VILAGRASA, 2012) e Bravissimo! 2-A2 (BIRELLO; VILAGRASA, 2013). A abordagem na qual se inspiram os manuais em questão é orientada à ação e se baseia em uma teoria segundo a qual "a língua é vista com um instrumento de uso para criar significado, no qual a interação torna-se a prioridade e o eixo sobre o qual gravita a aquisição da língua"12 (FERRONI, BIRELLO, 2016, p. 32, tradução nossa).

A fim de proporcionar uma aprendizagem orientada à ação, o manual Bravissimo! "propõe, no decorrer de cada unidade, uma série de atividades que os alunos deverão realizar para alcançar um objetivo final, apresentado na seção intitulada Il nostro progetto. Trata-se de situações semelhantes àquelas vividas fora da sala de aula e que encorajam fortemente o agir linguístico entre parceiros e a utilização de uma comunicação muito próxima à cotidiana"13 (BIRELLO; FERRONI, 2018, no prelo, tradução nossa). Ao encorajar o uso da língua semelhante àquele que ocorre na vida real, busca-se como consequência "a criação de espaços interativos nos quais os usos dos MD não somente se tornam naturais, como também necessários"14 (FERRONI ; BIRELLO, 2016, p. 33, tradução nossa). Os alunos inscritos no $5^{\circ}$ ano utilizaram o manual didático Nuovo Progetto Italiano 1, 2 e 3 (níveis A1, A2 e B1 do QCER, 2002) que favorece uma abordagem comunicativa e indutiva (MARIN, MAGNELLI, 2013, p. 1). Nos níveis avançados, porém, foram propostos materiais criados especificamente pelos docentes, que estimulam uma reflexão constante sobre os mecanismos linguísticos que produzem sentido através de uma cuidadosa análise textual.

11. A docente responsável pelo curso reside em São Paulo há cerca de 15 anos, é originária da Toscana e tem 42 anos. Formou-se em Literatura Moderna e Contemporânea na Università degli Studi di Firenze, se especializou em Didática de italiano como L2 e como LE na Università per Stranieri di Perugia e realizou mestrado e doutorado em Língua, Literatura e Cultura Italianas pela Universidade de São Paulo, no Brasil.

12. La lingua è vista come uno strumento atto a creare significato, in cui l'interazione diventa la priorità e il perno su cui gravita l'acquisizione della lingua (FERRONI, BIRELLO, 2016, p. 32).

13. Situazioni simili a quelle vissute al di fuori dell'aula che incoraggiano fortemente l'agire linguistico tra i patner e il ricorso ad una comunicazione molto prossima alla conversazione quotidiana (BIRELLO; FERRONI, 2018, no prelo).

14. La creazione di spazi interattivi in cui l'uso dei SD non solo diviene naturale quanto piuttosto necessario (FERRONI; BIRELLO, 2016, p. 33). 


\section{COLETA DE DADOS E METODOLOGIA}

Os dados foram coletados em dezembro de 2017, com o auxílio de uma câmera de vídeo, na presença da professora-pesquisadora. Os sujeitos - que foram informados previamente sobre o motivo da pesquisa - participaram voluntariamente do estudo e, antes de iniciar as gravações, preencheram uma autorização de consentimento para a circulação dos dados. O corpus é composto por um total de 60 minutos de gravação em vídeo, os quais foram transcritos integralmente pela pesquisadora ${ }^{15}$. É importante destacar que, no momento da redação deste artigo, encontra-se em andamento a ampliaçao do corpus de pesquisa, portanto os resultados deste estudo levam em conta as considerações parciais. As interações simétricas face a face têm duração de 10 minutos cada, totalizando 6 e são baseadas nas do grupo A.Ma.Dis ${ }^{16}$. As interações são semi-guiadas, uma vez que, aos participantes, antes de iniciar as gravações, foram fornecidas informações gerais sobre as situações: no decorrer da primeira simulação, foi solicitado decidir, junto ao colega, um presente para ser dado a um(a) companheiro(a) de faculdade; na segunda, deviam definir o que fazer com relação ao aumento do aluguel de um apartamento. As duplas, formadas livremente pelos estudantes, foram distribuídas do seguinte modo: Gabriele/Flavio, Giulia/Fernanda (estudantes do $1^{\circ}$ ano); Pedro/Carol, Tania/ Maia (estudantes do $5^{\circ}$ ano). Enquanto as duplas compostas por Gabriele/ Flavio e Pedro/Carol participaram de ambas as atividades, Fernanda/Giulia e Maia/Tania desenvolveram somente o primeiro role-play. Optamos por essa técnica de coleta de dados por uma série de razões. Em primeiro lugar, porque o role-play nos possibilitou controlar variáveis externas, como eventuais rumores de fundo, e também porque essa abordagem metodológica permite analisar de maneira pontual o processo de aquisição dos MD na fala dos aprendizes e a sua utilização em relação ao assunto em foco. Dito isso, no entanto, estamos conscientes dos inconvenientes que esse tipo

15. Os exemplos citados foram transcritos fielmente e podem conter algumas imprecisões com relação à língua-alvo. No que tange às convenções de transcrição, foram parcialmente modificadas as propostas por Van Lier (1988):

....,..., etc.: pausa breve;

$=:$ dois turnos de palavras em sobreposição;

((inc)), ((risadas)): o duplo parêntese indica incompreensível ou comentários sobre a transcrição, como risadas;

-: indica uma brusca interrupção;

::: os dois pontos repetidos por três vezes em sequência indicam um som prolongado;

?: entoação ascendente;

!: entoação descendente;

texto: fenômeno que se deseja destacar.

16. Em uma fase posterior da pesquisa será realizada uma comparação com os dados do grupo espanhol. 
de coleta de dados apresenta. De fato, os role-plays não garantem a espontaneidade dos dados, já que os interagentes interpretam papeis específicos; além disso, a naturalidade da cena é afetada pelo acompanhamento do pesquisador que, com sua presença, modifica o contexto da interação, situação denominada "paradoxo do observador", já avaliada por Labov (1970).

O método que adotamos para análise dos dados é quantitativo-qualitativo: em um primeiro momento, foram calculadas as ocorrências das interrupções, dos $\mathrm{MD}$ interacionais (por parte do falante e do interlocutor) e metatextuais para cada estudante e por níveis. Dada a polifuncionalidade sintágmática dos MD (BAZZANELLA, 2015, p. 37) ${ }^{17}$, em certos casos foram atribuídas mais de uma função ao mesmo MD.

\section{ANÁLISE DOS DADOS}

Passemos agora a comentar as funções dos MD e as estratégias interacionais utilizadas com vista à construção conjunta das interações, por meio da análise de alguns exemplos.

\subsection{Por parte do falante}

O MD mais recorrente utilizado por parte do falante, seja no nível inicial ou no avançado, é o sì (358 ocorrências) ${ }^{18}$. Vejamos o exemplo 1 retirado do nível inicial.

\section{Exemplo 1}

1Flavio: eh come::: come è un'amica che ((gesticulando)) come noi fare lettere ((enquanto Gabriele concorda)) penso che::: ..., magari..., gli piace un libro =

Flavio: eh como::: como é uma amiga que como a gente fazer letras penso que::: ..., talvez...; ele gosta de um livro $=$

2Gabriele: $=$ sì ((movendo a cabeça em sinal de aprovação) $)$ sì::: non non la conosco tanto bene per per sapere esattamente cosa regalarle ma::: un libro $=$

Gabriele: = sim sim::: não não a conheço muito bem para saber exatamente o que the dar de presente ma:::s um livro=

17. Por polifuncionalidade sintagmática entende-se a possibilidade de uma coexistência de valores a nível funcional (BAZZANELLA, 2015, p. 38).

18. Cfr., Tabela 3 nos ANEXOS. 
3Flavio: $=$ sì sì $(($ movendo a cabeça em sinal de aprovação e sorrindo $))$

Flávio $=\operatorname{sim} \operatorname{sim}^{19}$

Flavio e Gabriele estão decidindo qual presente dar a uma colega de curso. Flavio sugere um livro, considerando que se trata de uma estudante de Letras (turno 1). Gabriele manifesta concordância com o MD sì, reforçado pelo movimento da cabeça que indica aprovação, em seguida acrescenta que, não conhecendo muito bem os gostos da colega aniversariante, não saberia o que dar a ela, mas que um livro pode ser uma boa ideia (turno 2). Flavio se sobrepõe ao turno de Gabriele com o modificador sì para concordar com o colega, acompanhado de um gesto de aprovação e de um sorriso (turno 3). O sì desenvolve, nesse exemplo, como em muitos outros casos encontrados no corpus, uma dupla função: assinala concordância (turnos 1,3) e tomada de turno (turno 2). Assim como o MD sì, são igualmente produtivas as interjeições $\mathrm{eh}, a b m, m b$ (289 ocorrências), seguidas de prolongamentos vocálicos e pausas, sempre usadas como tomada de turno. Observemos o exemplo $2^{20}$.

\section{Exemplo 2}

1 Giulia: eh possiamo:::... comprare::: i biglietti per spettacolo perché Bruna piace molto::: la la musica

Giulia: eh podemos::.... comprar::: os ingressos para o espetáculo porque Bruna gosta muito::: música

2Fernanda: ((aprovando com a cabeça)) abm sì abm::: ...abm::: ...bo pensato bo pensato ora in::: abm:::... di fare $m b:::$ una torta di comprare una torta $=$

Fernanda abm sim abm:: abm... eu pensei eu pensei agora de:: abm:::1... em fazer mb::: um bolo comprar um bolo $=$

3Giulia: =sì::: ((aprovando com a cabeça)

Giulia: $=\operatorname{sim}::$ :

4Fernanda: prima di::: di di di salire...

Fernanda: antes de::: de de de subir...

19. Tentou-se traduzir as interações entre os alunos da maneira mais fiel possível, deixando transparecer os erros que eles cometem na LE. Contudo, não sendo sempre possível perceber as limitações dos aprendizes na LE através da tradução, pedimos ao leitor que considere que os participantes do estudo possuem nível A2 ou B1, e, por isso, podem ter dificuldades em se expressar de forma adequada, como evidenciam o elevado número de hesitações, prolongamentos de sons e repetições em suas falas"

20. Cfr., Tabela 3 nos ANEXOS. 
5Giulia: ((aprovando com a cabeça))

6Fernanda: eb::: eb::: dopo an-anda- andar-andarci al::: al cinema o al teatro e da- dargli dargli il biglietto

Fernanda: $e b_{:::} e b_{:::}$depois i-i-i-ir ao::: cinema ou ao teatro e da - dar a ele o ingresso

Giulia propõe presentear Bruna com um ingresso para um show (turno 1). Fernanda concorda e acrescenta, em uma sucessão de pausas cheias, alongamentos vocálicos, repetições e reformulações, que gostaria também de fazer um bolo (turno 2). Giulia se sobrepõe a Fernanda e, com a interjeição sì, consente (turno 3). Fernanda continua o turno sugerindo de presentear Bruna primeiramente com o bolo e, em seguida, com o ingresso (turno 4). A dificuldade de se expressar em italiano é novamente assinalada por prolongamentos vocálicos e interrupções, que marcam o início do turno 6. Os preenchedores de pausas são devidos à dificuldade de planejamento do discurso, ao mesmo tempo que demonstram as tentativas do falante em manter aberta a comunicação e a vontade de contribuir para a construção da conversação, apesar dos evidentes esforços. Embora isso ocorra principalmente no nível inicial (202 ocorrências), os participantes de nível avançado não estão excluídos (87 ocorrências).

Outro aspecto que chamou nossa atenção e que compreende ambos os níveis, é constituído por um consistente uso dos MD forse, penso che, possiamo, dobbiamo, facciamo, non so (503 ocorrências) ${ }^{21}$. Esses MD funcionam como: mecanismos de tomada de turno; mecanismos de modulação que diminuem o compromisso de assinalar o enunciado e preenchedores de pausas. São encontrados principalmente em correspondência com segundas partes de pares adjacentes (SCHEGLOFF, 1972), iniciadas por questões em que o falante solicita ao interlocutor que expresse, como especialista, sua própria opinião (exemplo 3 ).

\section{Exemplo 3}

1Carol: oggi è il 4 dicembre no? ((olhando o relógio $))=$

Carol: hoje é 4 de dezembro não? $=$

2Pedro: $=$ sì

Pedro: $=\operatorname{sim}$

3Carol: sta arrivando il compleanno di Camilla

Carol: está chegando o aniversário da Camilla

21. Cfr., Tabela 3 nos ANEXOS. 
4Pedro: sì

Pedro: sim

5Carol: cosa pensi di fare per lei?

Carol: o que você pensa em fazer para ela?

6Pedro: ..., non so perché..., non so volevo comprarla::: comprare per per per lei:::..., qualcosa di:: forse un libro:::come come Carolina come come Natalia ci ha detto

Pedro: ..., ñ̃a sei porque..., não sei queria comprá-la::: comprar para para para ela:::..., alguma coisa de::: talvez um livro::: como como Carolina como como Natália nos disse

7Carol: sì è una buona idea perché lei è stata molto tempo in Canada forse::: =

Carol: sim é uma boa ideia porque ela ficou muito tempo no Canadá talvez:::=

8Pedro: $=$ sì

Pedro: $=$ sim

9Carol: =lei manca i cose brasiliane no?

Carol: = ela falta as coisas brasileiras não?

10Pedro: forse::: qualcosa di Machado de Assis non so::: Paulo Coelho ((sorrindo)) non so

Pedro: talvez::: algo de Machado de Assis não sei::: Paulo Coelho não sei

No exemplo 3 Carol inicia a troca com duas perguntas "quebra-gelo" que pressupõem, por parte do interlocutor, um esforço mínimo em termos conversacionais, considerando-se que requerem um simples sinal de aprovação (do turno 1 ao turno 4). No turno 5, o preâmbulo pode se dizer concluído e Carol faz uma pergunta mais específica para saber que presente dar à Camilla. Após uma concatenação de estratégias discursivas, que consistem em pausas, associadas ao MD non so, repetido duas vezes e usado para ajudar a organizar a fala e para atenuar a proposta, Pedro sugere, mas somente no final do turno, que se compre um livro (turno 6). Carol acrescenta que para ela parece uma ótima ideia, especialmente porque a aniversariante mora no Canadá, assim pode lhe ser útil um livro em português (turnos 7 e 9). Pedro propõe dois autores por meio dos MD forse e non so, utilizados novamente com o valor do turno 6: ganhar tempo e mitigar uma proposta. A presença maciça dos MD forse, penso che, possiamo, dobbiamo, facciamo, non so, pode depender de diversos fatores: 1. o tipo de tarefa comunicativa que consiste propriamente em encontrar um acordo entre os falantes; 2. a relativa facilidade de usos dos MD - forse, non so, possiamo, penso che - quando comparados aos homônimos - magari, secondo me, io metterei, io farei, praticamente, voglio dire, cioè 3. 
as dificuldades de planejamento do discurso que induzem os falantes a usarem os indicadores de reformulação para ganhar tempo; 4 . como recurso para substituir os MD metatextuais argumentativos; 5 . as preferências linguísticas que cada falante possui.

Chama-nos a atenção o fato de que, na medida em que a competência linguística aumenta, os mecanismos de atenuação permanecem praticamente invariáveis, sem que se verifique a introdução de formas mais sofisticadas, como ocorre, por exemplo, com os participantes de nível avançado do corpus examinado por Jafrancesco (2015).

Ao contrário do que emerge dos estudos anteriores (PERNAS, GILLANI; CACCHIONE, 2011; CEKOVIĆ, 2014; FERRONI; BIRELLO, 2015), o uso da LM não é uma estratégia muito produtiva no contexto considerado por nós, mesmo entre os iniciantes ${ }^{22}$. Se e quando ocorre o uso da LM, diz respeito essencialmente aos $\mathrm{MD}$ metatextuais. Isso pode ser devido ao fato de que os $\mathrm{MD}$ metatextuais, que organizam o texto do ponto de vista da articulação e da estrutura argumentativa, requerem uma maior competência da $\mathrm{LE}$, que os nossos participantes nem sempre possuem. Veja-se o exemplo 4, no qual Fernanda sugere a Giulia presentear a colega de curso com um ingresso para um espetáculo teatral (turno 1). Giulia acolhe a proposta e acrescenta que, uma vez que Bruna gostou muito do curso sobre cavalaria, certamente irá gostar do presente. Não sabendo como expressar a consequência em italiano, usa o demarcativo português então com valor consecutivo (turno 2).

\section{Exemplo 4}

1Fernanda: io::: posso su- suggerire un::: uno spettacolo chiamato..., o Homem de la Mancha perché::: è::: su litteratura espagnola eh::: i personaggi::: eh:::..., como é que se fala ((olhando para Giulia)) eh::: ....ah il il personaggio è::: Don Don Quixote ((enquanto Giulia concorda com a acabeça)) de la de la Mancha eh::: suo ami- suo amico Sancho Panza

Fernanda: eu::: posso su- sugerir um::: um espetáculo chamado..., o Homem de la Mancha porque::: é::: sobre literatura espanhola eh::: os personagens::: eh:::..., como é que se fala eh::: ... ah o personagem é::: Dom Dom Quixote de la de la Mancha eh::: seu ami- seu amigo Sancho Pança

2Giulia: ah::: a Bruna piace molto::: un corso di:::caballaria então serà buonissima questa:::espettacolo:::

Giulia: ah::: Bruna gosta muito::: de um curso de::: cavalaria então será muito boa essa::: espetáculo:::

22. Cfr., Tabela 3 nos ANEXOS. 
Uma categoria que se apresenta exclusivamente nos participantes de nível inicial e que foi introduzida pelo manual Bravissimo! 2 (BIRELLO; VILAGRASA, 2013), com oportunas atividades de noticing e de reutilização, é a dos fatismos (32 ocorrências), usados para sublinhar "a coesão social da comunicação entendida como instrumento para criar, consolidar ou evidenciar o pertencimento de um indivíduo a um grupo" (BAZZANELLA, 1994:22, tradução nossa) ${ }^{23}$.

No exemplo 5, Gabriele pede ao companheiro, com um gesto envolvente, que expresse sua própria opinião.

\section{Exemplo 5}

1 Gabriele: perché qui nel nostro quartiere ci sono alcune facilità ((movendo as mãos)) come $=$ Gabriele: porque aqui no nosso bairro têm algumas facilidades como $=$

2Flavio: =sì

Flavio: $=\operatorname{sim}$

3Gabriele: il supermercato::: vicino qua eh:::

Gabriele: o supermercato::: aqui perto eh:::

4Flavio: il metro $=$

Flavio: o metrô $=$

5Flavio: $=$ il metro è molto facile per..., arrivare alla facoltà eh::: vedi che pensi della possibilità di eh::: ..., chiamare::: qualcuno della facoltà per ..., vivere con noi quindi così possiamo

Flavio: = o metrô é muito fácil para...; chegar à faculdade eh::: veja o que acha da possibilidade de::: ..., chamar::: alguém da faculdade para..., morar com a gente então assim podemos

Após um aviso de aumento de aluguel, Flavio e Gabriele devem decidir se deixam o local ou permanecem onde vivem. Na sequência, estão avaliando os pontos positivos do bairro que, segundo os estudantes, oferece muitos serviços: há um supermercado e é próximo ao metrô (do turno 1 ao 4). Gabriele acrescenta que graças ao metrô eles estão facilmente conectados à universidade e que uma alternativa poderia ser dividir as despesas de aluguel com um outro colega (turno 5). A proposta é formulada através do fatismo vedi (que havia sido apresentado em classe) que, além de trazer coesão ao tecido discursivo, agrega um grau de cumplicidade àquilo que os interagentes estão dizendo.

23. La coesione sociale della comunicazione intesa come strumento per creare, consolidare o evidenziare l'appartenenza di un individuo ad un gruppo (BAZZANELLA, 1994:22). 


\section{2 Por parte do interlocutor}

Uma das estratégias adotadas por parte dos interagentes consiste em concordar com o que foi dito pelo falante de turno ${ }^{24}$. Este traço, comum aos alunos de nível inicial (247 ocorrências) e avançado (111 ocorrências), contribui, como se evidencia no exemplo 6, para estabelecer um clima de participação e interesse entre os membros que participam da interação.

\section{Exemplo 6}

1 Pedro: Tatiana è una buona idea...

Pedro: Tatiana é uma boa ideia

2Carol: sì lei è responsabile:::una persona::: molto gentile:::no?

Carol: sim ela é responsável::: uma pessoa::: muito gentil::: não?

3Pedro: sì ..., ma penso che lei sarebbe una buona idea però non so se lei vuole $=$

Pedro: sim..., mas eu acho que ela seria uma boa ideia porém não sei se ela quer $=$

4Carol:=sì::anch'io ((concordando com a cabeça) $)$

Carol: $=$ sim::: eu também

5Pedro: $=$ vivere qui perché la sua relazione con i suoi genitori è buona $=$

Pedro: $=$ viver aqui porque a sua relação com os pais é boa $=$

6Carol: =è buona a lei pia- piace abitare con con loro non credo che:::

Carol: =é boa ela go- gosta de morar com eles não acho que::

7Pedro: che sia un problema perché $=$

Pedro: che seja um problema porque $=$

8Carol: $=$ non vedo:::la ragione

Carol: = não vejo::: a razão

9Pedro: sì lei lì vive gratuitamente

Pedro: sim ela lá vive gratuitamente

10Carol: è vero ((concordando com a cabeça))

Carol: é verdade

24. Cfr., Tabela 6 nos ANEXOS. 
11Pedro: dunque lei verrà qui pagando molto di più

Pedro: então ela virá aqui pagando muito mais

Pedro e Carol estão discutindo se é o caso ou não de compartilhar as despesas do aluguel com um terceiro colega. Após propor uma lista de nomes, que, por uma série de motivos, não convencem a ambos, Pedro cita o nome de Tatiana, enfatizando que "è una buona idea" (turno 1). Carol concorda plenamente com a sugestão com o MD sì, acrescentando que além de tudo é uma pessoa responsável e gentil e, então, conclui o turno com o MD no?, usado em tom ascendente, para obter uma posterior confirmação de Pedro (turno 2). Pedro se mostra novamente favorável com o MD sì, mas aponta que não se sabe se Tatiana deseja se mudar (turno 3). Carol, com uma sobreposição que não tem o intuito de tomar o turno, mas de manifestar sua concordância, demonstra que Pedro tem razão e reforça o consenso com o movimento da cabeça (turno 4). Pedro, no turno 5, continua expressando seu ceticismo e enfatiza que Tatiana tem uma ótima relação com os pais e que talvez não tenha a intenção de mudar de casa. Com a repetição dialógica (BAZZANELLA, 1994, p. 210) do adjetivo "è buona", Carol assinala consenso pelo que foi dito por Pedro (turno 6). O nível de cumplicidade entre os dois falantes é tão evidente que do turno 6 ao 8 há uma "construção vertical" (GUIL ET AL., 2008, p. 722) ${ }^{25}$, na qual a intervenção de um completa harmoniosamente a do outro e vice-versa. Como podemos notar por esse exemplo, o acordo, que subentende uma série de intenções entre os interagentes, é realizado com os MD interacionais sì, è una buona idea, è vero, usados pelo interlocutor para confirmar a própria atenção e demonstrar interesse na continuação do discurso, e se manifesta também através de sinais proxêmicos, que enfatizam o envolvimento e a concordância. Todos esses elementos desenvolvem uma função coesiva e contribuem para que a conversação progrida.

Observando a tabela 6, reproduzida nos anexos, nota-se que o sì é o MD interacional mais frequentemente utilizado para exprimir consenso ${ }^{26}$, podendo ser seguido de reforçadores nos níveis avançados: sì bravo, sì certo, sì è una buona idea, sì è vero (92 ocorrências). Mais esporádicas, por sua vez, são as ocorrêcias dos sinais va bene e esatto (3 ocorrências). O MD sì dai é usado no nível inicial para expressar envolvimento por parte do interagente e registra 7 ocorrências. Trata-se também de um sinal introduzido pelo manual didático Bravissimo! 2 (BIRELLO; VILAGRASA, 2013).

25. Costruzioni verticali (GUIL ET AL., 2008, p. 722).

26. 247 ocorrências no nível inicial e 111 ocorrências no nível avançado. 
Ao mesmo tempo, os interagentes não deixam de mostrar sua participação na conversa em andamento usando sinais que se sobrepoem ao turno do falante, com o intuíto de mostrar seu interesse na continuação do discurso e não de tomar a fala. É o que ocorre nos turnos 2 e 4 do exemplo 7, em que Gabriele, reiterando o sinal sì, demonstra atenção ao que é dito por Flavio.

\section{Exemplo 7}

1Flavio: sì... è::: c'è un problema che è::: noi ci conosciamo a tanto tempo ma... quindi penso che::: dato questo siamo più.... ahn... confiden- è confidenti di di di quello che $=$

Flavio: sim... é::: tem um problema que é::: nós nos conhecemos há muito tempo mas::: então eu acho que::: considerando isso somos mais::: ahn... confidentes que que que aquele que $=$

2Gabriele: $=$ sì sì $=$

Gabriele: $=\operatorname{sim} \operatorname{sim}=$

3Flavio: = è succedono... succe- succedeci ma::: è uno sconosciuto può essere pericoloso::: o no so

Flavio: $=$ é sucedem... suce- sucedem-nos mas::: é um desconhecido pode ser perigoso::: ou não sei

4Gabriele: sì sì $=$

Gabriele: $\operatorname{sim} \sin =$

Em ambos os níveis analisados, o $\mathrm{MD}$ sì - que pode ou não ser precedido da interjeição $m b b$ mbb - é o MD preferido pelos interagentes e é realizado simultaneamente ao turno anterior para sustentar o falante de turno. No nível avançado, diferentemente de pesquisas realizas anteriormente $\left(\mathrm{BINI}_{\text {; }}\right.$ PERNAS, 2008; GUILET AL., 2008; BORREGUER, 2009; GUIL; PERNAS; BORREGUERO, 2010; PERNAS; GILLANI; CACCHIONE, 2011; GUIL, 2015; JAFRANCESCO, 2015), não se registram ocorrências dos MD bene, sì veramente, davvero.

\subsection{As interrupções}

Há casos em que, antes de concluir seu turno, os participantes são interrompidos pelo interlocutor, que se auto seleciona e começa a falar sem esperar pelo Ponto de Relevância Transicional (transition-relevance place), ponto no qual se pode considerar potencialmente completo o turno e a transição é pertinente (SACKS; SCHEGLOFF; JEFFERSON, 1974), 
Essa modalidade de interrupção cria como efeito uma troca de turno "suave" (BAZZANELLA, 1994, p. 178) ${ }^{27}$, posto que a passagem não ocorre bruscamente, mas é assinalada por sinais precisos que dão a entender ao interlocutor que a troca não só é pertinente, mas também é consentida pelo falante de turno. Para compreender melhor, examinemos o exemplo 8, que tem como protagonistas Gabriele e Flavio.

\section{Exemplo 8}

1 Gabriele: eh::: ..., sai se:::..., abbiamo eh::: la possibilità di di di::: parlare con questo proprietario perché mi ricordo che tu hai hai ((enquanto Flavio concorda)) deciso::: tutte le cose::: dell'affitto $=$

Gabriele: eh::: ..., sabe se::::.., temos eh::: a possibilidade de de de::: falar com esse proprietário porque me lembro que você tem tem::: decidido::: todas as coisas:: do aluguel=

2Flavio: $=$ sì $(($ enquanto concorda com a cabeça) $)$

Flavio: $=\operatorname{sim}$

3Gabriele: =quando abbiamo cambiato di casa quando abbiamo trasferito di qua eh::: ((gesticulando animadamente) $)$ conosci lui? per per tentare per tentare di parlare con lui::: cercare qualche::: soluzione :::

Gabriele: = quando mudamos de casa quando nos transferimos daqui eh::: conhece ele? para para tentar para tentar falar com ele::: procurar alguma::: solução

4Flavio: posso parlare con lui però::: ..., lui sembra una persona ((sorriem)) una persona brutta in in questo::: in questo caso $\mathrm{mhm}$ non non lo so se..., se::: se lui::: eh::: ...eh ((movendo as mãos)) ...., farà qualcosa per per per::: $=$

Flavio: posso falar com ele porém::: ..., ele me parece uma pessoa uma pessoa difícil em em nesse::: nesse caso mhm não não sei se....., se::: se ele::: eh::: eh..., fará alguma coisa para para para::: $=$

5Gabriele: $=$ aiutarci

Gabriele: $=$ nos ajudar

6Flavio: aiutarci eh::: po- posso parlare con lui

Flávio: nos ajudar eh::: po- posso falar com ele

Gabriele, no turno 1, sugere a Flavio que se converse com o proprietário da casa para ver se é possível entrar em um acordo (turno 1). Flavio manifesta o seu consenso com o sinal de atenção sì (turno 2). Gabriele acrescenta que a pessoa mais adequada para falar com o proprietário é o próprio Flavio, porque o conhece (turno

27. Morbida (BAZZANELLA, 1994, p. 178). 
3). Flavio aceita a proposta, mas argumenta, com auxílio do demarcativo però, que o proprietário, não sendo uma pessoa fácil, provavelmente não aceitará. Próximo à parte final do turno, Flavio demonstra evidentes dificuldades na articulação de sua fala, atestadas por repetições contínuas, pausas, prolongamentos sonoros e hesitações (turno 4). Gabriele, que compreende o embaraço no qual está o companheiro, em virtude de sua maior competência, vem em auxílio e se sobrepõe à fala de Flavio, sugerindo-lhe o termo que ele estava procurando, "aiutarci" (turno 5). A sequência se conclui com a sugestão lexical que é aceita de bom grado por Flavio, incorporando-a a própria fala (turno 6).

A interrupção realizada por Gabriele insere-se no tipo de interrupção suportiva (BAZZANELLA, 1994, p. 188). Com efeito, almeja mais do que nunca apoiar a mudança de turno, dando vida a uma verdadeira "sequência da pedagogia natural". (ORLETTI, 2000, p. 121) ${ }^{28}$. Essas sequências, cujo objeto é a língua e a reflexão metalinguística, interrompem momentaneamente a interação em andamento, uma vez que visam à solução de eventuais problemas de natureza linguística, favorecendo assim a compreensão mútua, por meio de estratégias de negociação, visando à co-construção da interação. Ao implementá-las, os interagentes redefinem temporariamente os papéis de especialista e aprendiz, que serão negociados com base nas competências lingüísticas possuídas por cada falante (ORLETTI, 2000, p. 121). As dificuldades discursivas são principalmente lexicais e, como no exemplo 8, são sinalizadas por uma série de indícios, como pausas, prolongamentos sonoros, risos, repetições e, ainda, uso da LM para substituir o termo cujo correspondente exato em italiano é desconhecido. O pedido de ajuda por parte do falante pode ser assinalado pelos MD come si dice?, come posso dire?, non so (45 ocorrências no nível inicial e 12 no avançado ${ }^{29}$. Esses MD são pronunciados com entonação ascendente no fim do turno e indicam disponibilidade de ceder o turno ao falante mais competente, como notamos no próximo exemplo.

\section{Exemplo 9}

1 Pedro: ma::: non so perché il libro è interessante forse possiamo possiamo comprare un::: un::: un:::una::: novela por- eh::: brasiliana $=$

Pedro: mas::: não sei porque o livro é interessante talvez podemos podemos comprar uma::: uma::: um::: uma::: novela par- eh::: brasileira $=$

28. Sequenza di pedagogia naturale (ORLETTI, 2000, p. 121).

29. Cfr., Tabela 8 nos ANEXOS. 
2Carol: =sì::: è una bella idea

Carol: $=$ sim::: é uma boa ideia

3Pedro: per lei una novela italiana

Pedro: para ela uma novela italiana

4Carol: bravo ((sorrindo))

Carol: ótimo

5Pedro: non so..., perché lei anche pia- eh::: era buono per lei lei piaceva del- delle novele brasiliane ((enquanto Carol concorda)) durante le lezioni::: però adesso lei non non guarda nulla

Pedro: não sei..., porque ela gos- também eh::: era bom pra ela ela gostava da- das novelas brasileiras durante as aulas::: mas agora ela não não assiste nada

6Carol: ((concordando) $)$ può essere metà di noi possiamo dare questi libri e l'altra metà può:::

Carol: pode ser metade de nós podemos dar esses livros e a outra metade pode:::

7Pedro: ((concordando)) dare questa novela come si dice novela in italiano telenovella? giusto? ((olhando para Carolina de forma interrogativa))

Pedro: dar essa novela como se diz novela em italiano telenovela? certo?

8Carol: credo di no ((sorrindo))

Carol: acho que não

9Pedro: e la festa come sarà?

Pedro: e a festa como será?

Carol propõe que se presenteie uma amiga em comum com um livro. Pedro, no entanto, não está totalmente convencido e sugere uma telenovela brasileira. Não sabendo o termo exato em italiano, recorre inicialmente ao termo brasileiro "novela" (turno 1). Após uma série de negociações (do turno 2 ao turno 5), Carol aceita a proposta e acrescenta que deseja presentear a colega com as duas coisas (turno 6). Nesse ponto, Pedro, que não está seguro da exatidão terminológica, usa o indicador de reformulação come si dice para pedir confirmação se o termo correto em italiano é telenovela e, com o MD giusto?, pronunciado no fim do enunciado, pede ajuda à companheira (turno 7). Carol, no entanto, não consegue resolver a dúvida e, com um sorriso, manifesta seu desconforto. Pedro então intervém prontamente e, mudando de assunto, faz a conversa prosseguir (turno 9). Essa atividade de coconstrução de interação ocorre naturalmente e não é percebida como uma forte 
ameaça para as faces positivas ou negativas dos falantes (BROWN, LEVINSON, 1987), uma vez que ocorre em um contexto de comunicação exolinguística, isto é, um contexto caracterizado pela assimetria de divergência entre os repertórios linguísticos dos interagentes (LÜDI, PY, 2003), onde a contribuição do falante mais experiente é fortemente esperada pelos outros participantes (BIRELLO; FERRONI, 2013).

Juntamente às "construções verticais" (GUIL; PERNAS; BORREGUERO, 2008, p. 722) ${ }^{30}$, aparecem, embora em menor quantidade, as interrupções competitivas (BAZZANELLA, 1994, p. 189) ${ }^{31}$.

Diferentemente das interrupções suportivas, as interrupções competitivas dão lugar a mudanças de turno "não suaves" (BAZZANELLA, 1994, p. 178), verificadas nos níveis avançados - e no nível inicial por parte de Gabriele, aluno que demonstra uma maior competência em italiano LE em relação aos colegas. Se a ativação de uma interrupção suportiva desencadeia uma relação colaborativa entre o falante e o interlocutor, na qual o falante mais experiente vem em auxílio de quem está temporariamente em dificuldade, com as interrupções competitivas, quem interrompe não o faz com intenção de ajudar o outro, mas de expor a própria opinião que não coincide exatamente com a de seu colega. Dessa forma, o falante manifesta, aos olhos do parceiro e da pesquisadora, certa "superioridade" em termos discursivos, como emerge do exemplo 10.

\section{Exemplo 10}

1 Gabriele: io so che:::Giuliana non vive qua eh::: la sua abitazione è::: ((gesticulando)) è lontano di qua ((enquanto Flavio concorda)) ma penso che::: eh::: lui lei sta sempre qua alla Usp quindi possiamo vedere::: non so..., forse eh::: forse un un'aula disponibile ((Flavio continua a concordar)) qua però per fare una piccola festa

Gabriele: eu sei que::: Giuliana não mora aqui eh::: a sua casa é::: é longe daqui mas acho que::: eh::: ele ela está sempre aqui na USP então podemos ver::: não sei..., talvez eh::: talvez uma sala de aula disponível aqui mas pra fazer uma pequena festa

2Flavio: sì possiamo parlare con la professoressa sì ((Gabriele concorda)) se è possibile fare::: un po'::: se può dare un po' di tempo dellla della=

Flavio: sim podemos falar com a professora sim se é possível fazer::: um pouco::: se pode liberar um pouco de tempo da $\mathrm{da}=$

3Gabriele: =della nostra lezione d'italiano?

Gabrie: $=$ da nossa aula de italiano?

30. Costruzioni verticali (GUIL; PERNAS, BORREGUERO, 2008, p. 722).

31. Cfr., Tabela 9 nos ANEXOS. 
4Flavio: sì sì

Flavio: sim sim

5Gabriele: eh siamo quasi al fine del corso $=$

Gabriele: eh estamos quase no final do curso $=$

6Flavio: = sì sì $=$

Flavio: $=\operatorname{sim} \operatorname{sim}=$

7Gabriele: penso che non possiamo più avere tempo $=$

Gabriele: acho que podemos não ter mais tempo=

8Flavio: questa mi sembra::: una boa ideia eh::: perché:::...così tutti::: ((movendo as mãos)) colleghi::: sara- saranno? ((olhando para Gabriele em modo interrogativo))

Flavio: essa me parece::: uma boa ideia eh::: porque:::... assim todos::: colegas::: esta- estarão?

9Gabriele: è sì

Gabriele: é sim

10Flavio: saranno::: qua ((movendo as mãoes) $)$ insieme e::: possiamo festeggiare insieme= ((sorrindo))

Flavio: estarão::: aqui juntos e::: podemos festejar juntos

11 Gabriele: $=$ ma facciamo facciamo una cosa che::: lei non scopre

Gabriele: =mas façamos façamos uma coisa que... ela não descobre

12Flavio: sì sì=

Flavio: $\operatorname{sim} \operatorname{sim}=$

13Gabriele: =forse possiamo fare un gruppo creare un gruppo nel whatsApp ((enquanto Flavio concorda)) e::: mandare un messaggio per tutti i nostri colleghi eh::: i nostri amici dei corsi del corso e::: forse lei possiamo chieder-chiergli di::: portare qualcosa da bere o da mangiare che ne pensi?

Gabriele: =talvez possamos fazer um grupo criar m grupo no WhatsApp e::: mandar uma mensagem para todos os nossos colegas eh::: os nossos amigos do curso do curso e::: talvez possamos pedir- pedir-lhes para::: trazer algo de comer ou de beber o que você acha?

14Flavio: sì sì sì è::: è una buona idea ma::: bisogna di essere una sorpresa

Flavio: sim sim sim é::: uma boa ideia mas::: tem que ser uma surpresa

15Gabriele: mhm mhm

Gabriele: mhm mhm

16Flavio: eh::: per questo::: è:::magari no $(($ movendo as mãos $)) \ldots$, trazer? $=(($ olhando para 
Gabriele em modo interrogativo))

Flavio: eh::: por isso::: é::: talvez não..., trazer?

17Gabriel: $=$ non portare

Gabriel: não trazer

18Flavio: non portare:::tutti nelle lezioni $=$

Flavio: não trazer::: todos nas aulas $=$

19Gabriele: =ma magari possiamo::: chiedere alla professoressa per fare la la festa eh nell'inizio nella parte iniziale della nostra lezione

Gabriel: = mas talvez possamos:: pedir para a professora para fazer a a festa eh no início na parte inicial da nossa aula

20Flavio: sì sì

Flavio: sim sim

21 Gabriele: qui e tutti i colleghi arrivano fra le sette e venti sette e venticinque ((enquanto Flavio concorda)) eh::: possiamo preparare tutto prima di Giuliana arrivare e quando lei arriva siamo tutti pronti

Gabriele: aqui e todos os colegas chegam entre sete e vinte e sete e vinte e cinco eh::: podemos preparar tudo antes da Giuliana chegar e quando ela chega estamos todos prontos

Flavio e Gabriele estão decidindo onde comemorar o aniversário de Giuliana. Uma vez que Giuliana passa muito tempo na faculdade, Gabriele propõe que se faça a festa em sala de aula (turno 1). Flavio aceita e acrescenta que poderiam pedir à professora que disponibilizasse uma parte da aula para realizar a festa. Não sabendo ou não se lembrando como dizer "aula" em italiano, começa a vacilar (turno 2). Gabriele compreende a dificuldade e ajuda o companheiro com uma interrupção suportiva na qual sugere o termo (turno 3). Do turno 4 ao 10 os colegas definem, por meio de uma modalidade colaborativa, caracterizada pela repetição do sinal de acordo sì, os detalhes da festa. No turno 11 Gabriele, com uma interrupção competitiva, rouba a cena de Flavio e com o MD ma, que serve seja para tomar a fala quanto para acrescentar informação, propõe que se faça uma festa surpresa. Em seguida, elabora um enunciado extenso e bem articulado, introduzido pelo MD forse e sugere que se crie um grupo no WhatsApp (turno 13). A superioridade discursiva de Gabriele em relação a Flavio é atestada por uma nova sugestão lexical do termo "trazer" em italiano (turno 17) e por uma interrupção competitiva, realizada com o MD ma magari, para propor que se faça a festa no início da aula.

Essas construções, que definimos como "construções divergentes", são facilmente reconhecíveis, uma vez que são introduzidas pelos MD demarcativos 
com função argumentativa como no però, sì però, ma, ou pelos moduladores com função mitigadora non so, forse, no perché, ma magari que interrompem o turno do falante sem esperar que o Ponto de Relevância Transicional seja alcançado (SACKS, SCHEGLOFF; JEFFERSON, 1974), para fazer uma contraproposta. Em geral, a troca de opiniões se desenvolve de modo harmonioso: a proposta do colega mais competente é aceita sequencialmente, sem dar lugar a sucessivas divergências, as quais poderiam gerar conflitos e requerer um maior empenho discursivo ${ }^{32}$.

\section{RESULTADOS}

Passemos agora aos resultados, relativos à frequência de uso dos MD por micro categorias e níveis e pelas interrupções.

Tabela 9. Total de marcadores discursivos e interrupções por nível

\begin{tabular}{|l|c|c|}
\hline MARCADORES DISCURSIVOS & NÍVEL INICIAL & NÍVEL AVANÇADO \\
\hline Tomada de turno falante & 687 & 504 \\
\hline Pedido de atenção falante & 0 & 0 \\
\hline Sinais relativos ao discurso falante & 4 & 9 \\
\hline Controle da recepção falante & 0 & 0 \\
\hline Fatismos falante & 32 & 0 \\
\hline Mecanismos de modulação falante & 213 & 290 \\
\hline Confirmação de atenção interlocutor & 355 & 206 \\
\hline Confirmação de acordo e back-channels interlocutor & 49 & 45 \\
\hline Fatismos interlocutor & 32 & 0 \\
\hline Demarcativos & 4 & 12 \\
\hline Focalizadores & 2 & 15 \\
\hline INTERRUPÇÕES & 34 & 12 \\
\hline Interrupções suportivas & 6 & \\
\hline Interrupções competitivas & & \\
\hline
\end{tabular}

32. A este propósito sugerimos que se veja o estudo de Ferroni (2017), no qual se registram muitas estratégias utilizadas durante uma conversação face a face entre falante de italiano LM como discursos simultâneos, sobreposições, interrupções e MD metatextuais e moduladores, que tecem a trama da interação e sustentam as intervenções dos falantes, a fim de afirmar e refutar, de maneira mais ou menos acesa, as próprias opiniões. 
Como podemos notar, a tomada de turno, realizada predominantemente por meio do MD sì e das hesitações, representa a categoria mais representativa (687 inicial/594 avançado). Esse dado pode explicar-se pelo fato de que, para poder desenvolver a tarefa comunicativa proposta, os estudantes devem interagir entre si para alcançar um acordo final, mas também porque os participantes encontram muitas dificuldades de planejamento do discurso. Com efeito, à medida que os estudantes adquirem maior fluência, as hesitações diminuem (207 inicial e 87 avançado). Pelo mesmo motivo, igualmente frequentes são os mecanismos de atenção, de acordo e os back-channels usados por parte do interlocutor (400 inicial e 251 avançado) que, além de requerer um baixo esforço em termos linguísticos, uma vez que são principalmente expressos com um simples sì ou com o movimento da cabeça, ajudam a preencher eventuais "embaraços comunicativos" diante dos olhos da câmera e da pesquisadora. Os dados indicam ainda que, embora as ocorrências dos MD demarcativos no però, sì però, ma, no perché, sejam bastante baixas (6 inicial/12 avançado), os falantes de ambos os níveis não renunciam a argumentar e o fazem especialmente por meio dos moduladores non so, forse, penso che, facciamo, ma magari (213 inicial e 290 avançado), que, entre as diversas funções, desempenham também a argumentativa. Os fatismos dimmi, sai, vedi, ocorrem somente no nível inicial (32 ocorrências), notando-se, ainda, a ausência das chamadas de atenção e recepção por parte do falante. Isso pode depender do fato de que são pouco produtivos no gerenciamento da tarefa comunicativa atribuída; de fato, é uma microcategoria particularmente presente nas trocas assimétricas e que caracteriza, em contextos escolares, a fala dos professores (ORLETTI, 2000). Do ponto de vista qualitativo, o que chama a atenção é o fato de que os indicadores de reformulação são expressos, mesmo nos níveis avançados, por meio de uma gama muito limitada de $\mathrm{MD}$, o que não inclui formas como praticamente, diciamo, cioè, voglio dire. Esses $\mathrm{MD}$, a nível conversacional, podem ser muito úteis para gerenciar interações exolíngues, porque ajudam a ganhar tempo e a organizar o próprio discurso.

\section{CONCLUSÕES}

Para construir conjuntamente uma interação, é essencial que os interagentes, sejam eles nativos ou não nativos, se envolvam mutuamente através do uso de recursos interacionais específicos que consistem em saber como gerenciar o turno e as interrupções, demonstrar interesse naquilo que o falante de turno está dizendo, pedir e fornecer esclarecimentos, reformular sua própria fala ou a do falante. 
Uma vez que, como enfatiza Walsh (2016, p. 62), é muito mais importante ser confluente do que fluente para fins de eficácia comunicativa, este artigo procurou analisar, a partir de uma perspectiva conversacional, o desenvolvimento da competência interacional, com particular atenção aos $\mathrm{MD}$ e às interrupções, em alunos de italiano como LE, durante conversas semi-guiadas. A pesquisa permitiu obter informações sobre a interlíngua dos participantes, as quais podem, posteriormente, ser aplicadas para a elaboração de percursos formativos específicos a serem utilizados em sala de aula.

O estudo, ainda em andamento, realizado com alunos de italiano LE matriculados no primeiro e último ano do curso de Letras/Italiano na Universidade de São Paulo, mostrou que, para realizar as tarefas comunicativas atribuídas, uma amostra significativa de MD foi empregada. Destacam-se, entre todos, os marcadores de interação para concordar, usados tanto pelo falante como pelo interlocutor. A presença maciça de marcadores de interação para concordar, associada a um uso esporádico de interrupções competitivas e MD metatextuais, parece indicar que os alunos que participaram deste estudo, incluindo aqueles em um nível avançado, são pouco propensos à cultura da discussão. Contudo, apesar das repetidas dificuldades manifestadas no gerenciamento da comunicação, os alunos não se isentam da tarefa designada, mas fazem o melhor possível para manter viva a conversação, o que pode ser devido também à presença da câmera e da pesquisadora, que inevitavelmente modificam o contexto da pesquisa. O esforço dos alunos em manter o fluxo da conversação fez com que nas interações despontassem uma série marcadores de concordância, fatismos, construções verticais e pedidos de ajuda que demonstram que os alunos, dentro do nível de competência linguístico-comunicativa de cada um, se empenham em não falhar no contrato de comunicação assumido e se ajudam mutuamente no esforço de co-construir o tecido conversacional. As construções verticais, que visam à resolução de problemas de natureza linguística, são menos usadas por falantes de nível avançado, que preferem mostrar suas habilidades interpessoais através de construções divergentes, as quais requerem o uso de específicos MD metatextuais para argumentar. Tratando-se de uma tarefa comunicativa muito específica e que, em termos conversacionais, pressupõe uma atividade contínua de confronto de opiniões, nos níveis inicial e avançado a argumentação se dá pelo uso de mecanismos de modulação que, pelo seu valor pragmático, são mais fáceis de usar em comparação com os MD metatextuais. Chama-nos a atenção que as variedades de MD interacionais e metatextuais não difiram muito entre os aprendizes do nível inicial e avançado. Apenas os MD para expressar concordância são realizados no nível avançado através de uma variedade muito mais ampla em comparação com o 
nível inicial. Com relação aos fatismos, estes são utilizados única e exclusivamente no nível inicial. Esse dado nos faz supor que não necessariamente a um nível de competência mais elevado corresponda uma gama mais ampla de $\mathrm{MD}$, mas que outros fatores influenciam na interlíngua dos estudantes, como o insumo e as atividades realizadas em aula para notar determinadas formas.

Com base nos resultados obtidos, a pesquisa oferece preciosas indicações didáticas sobre o tipo de propostas a serem desenvolvidas em classe para ampliar a competência procedural no aluno. Em primeiro lugar, é importante oferecer aos estudantes maiores ocasiões para discutir entre eles, considerando-se que os dados indicam que são pouco propensos à cultura da discussão, da sobreposição e das interrupções, talvez porque as atividades desenvolvidas em sala de aula são inadequadas no que se refere ao tratamento desse tópico.

Esses elementos discursivos tecem a trama da interação e ajudam os falantes a afirmar e a argumentar contra, colocando de modo mais ou menos aceso as próprias opiniões (FERRONI, 2017, p. 52). Sobre esse propósito, pode ser útil expor os alunos a textos orais autênticos que reproduzam discussões entre nativos, pois de fato "é só conhecendo as características da comunicação real que se poderá ajudar o aluno a usar a língua de modo adequado aos diversos contextos (ZORZI, 1996, p. 15, tradução nossa) ${ }^{33}$. Além disso, é importante ampliar o repertório dos $\mathrm{MD}$, combinando atividades específicas de observações que permitam notar, desde os níveis iniciais, como gerenciar, por meio da utilização de oportunos indicadores de reformulação que ajudam a ganhar tempo e a organizar o próprio discurso, eventuais impasses comunicativos e a aptidão para expor as próprias opiniões e alcançar um acordo com a ajuda de mecanismos específicos de modulação e dos MD demarcativos e focalizadores. Na fase de produção, poderiam, por sua vez, ser organizadas atividades análogas às descritas, como as de role-play, gravando-as e solicitando aos alunos que as transcrevam e desenvolvam atividades de autoobservação que os levem a melhorar a qualidade das performances orais em termos interacionais. Por fim, para promover uma cultura da interação, a proposta do manual Bravissimo! 2 demonstrou ser uma estrada interessante a se percorrer, pois, graças à presença de "espaços interativos" (FERRONI, BIRELLO, 2016, p. 49) ${ }^{34}$ compartilhados entre pares, oferece aos estudantes a possibilidade de reutilizar, em um contexto significativo, as regras que governam o andamento da conversação na língua alvo de estudo.

33. È solo conoscendo le caratteristiche della comunicazione reale che si potrà aiutare lo studente ad usare la lingua in modo adeguato ai diversi contesti (ZORZI, 1996, p. 15).

34. Spazi interattivi (FERRONI, BIRELLO, 2016, p. 49). 


\section{REFERÊNCIAS}

BAZZANELLA C. (2015). Segnali discorsivi a confronto. Dati e teoria, un percorso integrato. Iin Borreguero Zuloaga M.; Gómez-Jordana Ferary S. (orgs.), Les marqueurs du discours dans le langues romanes: une approche contrastive, Limoges: Lambert-Lucas, pp. $35-46$

BAZZANELLA, C. (2006). Discourse Markers in Italian: towards a 'compositional' meaning. In: Fischer, K. (org.), Approaches to discourse particles. Amsterdam: Elsevier, pp. 449-464.

BAZZANELLA, C. (1994). Le facce del parlare. Firenze: La Nuova Italia.

BAZZANELLA, C. (1995). I segnali discorsivi. In: Renzi, L.; Salvi, G.; Cardinaletti, A. (orgs.), Grande grammatica italiana di consultazione, vol. III. Bologna: Il Mulino, pp. 226257.

BINI M.; PERNAS, A. (2008). Marcadores discursivos en los primeros estadios de adquisición del italiano L2. In: Monroy, R.; Sánchez, A. (orgs.), 25 años de Linguiística Aplicada en España: bitos y retos. Actas del VI Congreso de la Asociación Española de Lingüística Aplicada (AESLA), Murcia, Edit.um. [CD-Rom], pp. 25-32.

BIRELLO, M.; FERRONI. (no prelo). Italian discourse markers and TBLT approach. A study from a conversational analisys perspective. In: Iria Bello, M.; Calvi, V.; Landone, E. (orgs.), Cognitive Insights in Discourse Markers in Second Language Acquisition. Bern: Peter Lang.

BIRELLO, M.; VILAGRASA, A. (2014). Bravissimo! 3 Corso d'italiano. Barcellona: Edizioni Casa delle Lingue.

BIRELLO, M.; FERRONI, R. (2013). Giochi di identità e uso delle lingue nella classe di italiano lingua straniera. Rassegna Italiana di Linguistica Applicata, v. 45, nº 2, pp. 21-34.

BIRELLO, M.; FERRONI, R. (2018). Italian discourse markers and TBLT approach. A study from a conversational analisys perspective. In: Bello, I.; Calvi, M. V.; Landone, E. (orgs.), Cognitive Insights in Discourse Markers in Second Language Acquisition. Bern: Peter Lang, (no prelo).

BIRELLO, M.; VILAGRASA, A. (2013). Bravissimo! 2 Corso d'italiano. Barcellona: Edizioni Casa delle Lingue.

BIRELLO, M.; VILAGRASA, A. (2012). Bravissimo! 1 Corso d'italiano. Barcellona: Edizioni Casa delle Lingue. 
BORREGUERO M.; PERNAS P. (2009). Cortesia e scortesia in un contesto di apprendiento linguistico: la gestione dei turni. In: Pettorino, M.; Giannini, A.; Doveto, F. M. (orgs.), La comunicazione parlata 3. Atti del terzo congreso internacionales del Gruppo di Studio sull Comunicazione Parlata. Napoli: Università degli Studi di Napoli l'Orientale Vol. I., pp. 227-247.

BRAVO, D. (2004). Cortesía verbal codificada cortesía verbal interpretada em la conversación. In: Bravo, D.; Briz, A. (orgs.), Pragmática sociocultural: estudios sobre el discurso de cortesía en español. Barcelona: Ariel Letras, pp. 67-93.

BROWN, P.; LEVINSON, S. (1987). Politeness. Some universals in language usage. Cambridge: Cambridge University Press.

CEKOVIĆ, N. (2014). I segnali discorsivi nell'interlingua degli studenti universitari di italiano L2. Italica Belgradensia, v. 2, nº 1, pp. 193-110

FERRONI, R. (2017). Analisi di una conversazione tratta da un dominio professionale: la gestione di una discussione fra parlanti d'italiano. Caligrama: Revista de Estudos Românicos,v. 22, nº2, pp. 33-60.

FERRONI, R.; BIRELLO, M. (2016). Meta-analisi e applicazione di una proposta didattica orientata all'azione per l'apprendimento dei segnali discorsivi in italiano LS. Italiano LinguaDue, v. 8, $\mathrm{n}^{\circ} 1$, pp. 30-53.

FERRONI, R.; BIRELLO, M. (2015). "Bueno stiamo praticando": análise comparativa dos sinais discursivos utilizados em situações interativas entre aprendizes de línguas próximas. Trabalbos em Linguística Aplicada, v. 54, n 1 , pp. 483-517.

GILLANI, E.; PERNAS, P. (2013). Input orale e copetenza dialogica: le scelte dei manuali di italiano Ls. Studi Italiani di Linguistica Teorica e Applicata , v. 42, n 1, pp. 61-99.

GUIL P.; BAZZANELLA C.; BINI M.; PERNAS, P.; GIL T.; BORREGUERO M.; PERNAS, A., KONDO, C.; GILLANI, E. (2008). Marcadores discursivos y cortesía lingüística en la interacción de aprendices de italiano L2. In: Briz A. (org.), Cortesía y conversación: de lo escrito a lo oral. Actas del III Coloquio Internacional del Programa EDICE. Universidad de Valencia y Programa EDICE, Valencia, pp. 711-729.

GUIL P.; PERNAS P.; BORREGUERO, M. (2010). Descortesía en la interacción dialógica entre aprendices hispanófonos de italiano L2. In: Orletti, F.; Mariottini, F. (orgs.), (Des)cortesía em español. espacios teóricos y metodológicos para su estúdio. Università Roma Tre, Programa EDICE, Stockholm University Roma, pp. 679-704. 
GUIL, P. (2015). Marcadores discursivos en la interlengua de aprendices de italiano L2. In: Borreguero Zuloaga, M.; Gómez-Jordana Ferary, S. (orgs.), Les marqueurs du discours dans les langues romanes: une approche contrastive. Limoges: Lambert-Lucas, pp. 373-385

HAVERKATE, H. (1994). La cortesía verbal. Estudio pragmalingiuístico. Madrid: Gredos.

JAFRANCESCO, E. (2015). L'acquisizione dei segnali discorsivi in italiano L2. Italiano LinguaDue, v. 1, n ${ }^{\circ}$, pp. 1-39.

KRAMSCH, C. (1986). From language proficiency to interactional competence. The Modern Language Journal, v. 70, n 14 , pp. 366-372.

LABOV, W. (1970). The study of language in its social context. Studium Generale, v. 23, n 1, pp. 30-87.

LÜDI G.; PY B. (2003). Etre bilingue. Berna: Peter Lang.

MARIN, T.; MAGNELLI, S. (2013). Nuovo progetto italiano 1a. Roma: Edilingua, 2013

NUZZO, E.; SANTORO, E. (2017). Apprendimento, insegnamento e uso di competenze pragmatiche in italiano L2/LS: la ricerca a partire dagli anni Duemila. E-JournALL, v. $4, \mathrm{n}^{\mathrm{o}} 2$, pp. $1-27$.

ORLETTI, F. (2000). La conversazione diseguale: potere e interazione. Roma: Carocci.

PEKAREK DOEHLER, S.; POCHON-BERGER, E. (2015). The development of L2 interactional competence: evidence from turn-taking organization, sequence organization, repair organization and preference organization. In: Cadierno, T.; Eskildsen, S. (orgs.), Usage-based perspectives on second language learning. Berlin: Mouton De Gruyter, pp. 233-267.

PERNAS P.; GILLANI, E., CACCHIONE, A. (2011). Costruire testi, strutture conversazionali: la didattica dei segnali discorsivi comw wlementi pivot dell'interazione verbale. Italiano LinguaDue, v. 1, n ${ }^{\circ} 1$, pp. 65-138.

Quadro comune europeo di riferimento per le lingue: apprendimento insegnamento valutazione. (2002). Firenze: La Nuova Italia-Oxford.

SACKS, H.; SCHEGLOFF, E.; JEFFERSON, G. (1974). A simplest systematic for the organization of turn-taking in conversation. Language, v. 50, $\mathrm{n}^{\mathrm{O}} 1$, pp. 696-735. 
SCHEGLOFF, E. (1972). Sequencing in conversational openings. In: Gumperz, J.; Hymes,

D. (orgs.), Directions in sociolinguistics: the ethnograpby of communication. New York: Holt, pp. 346-379.

VAN LIER, L. (1988). The classroom and the language learner. London: Longman.

WALSH, S. (2016). Sviluppare la competenza interazionale in classe. In: Andorno C.; Grassi R. (orgs.), Le dinamiche dell'interazione. Prospettive di analisi e contesti applicativi. Milano: Studi AitLA, pp. 61-76.

YOUNG, R. (2011). Interactional competence in language learning, teaching, and testing. In: Hinkel, E. (orgs.), Handbook of research in second language teaching and learning. London \& New York: Routledge, pp. 426-443.

ZORZI, D. (1996). Contributi dell'analisi della conversazione all'insegnamento dell'italiano L2. In: Maggini, M. (Org.), Atti del III congresso ILSA, Comune di Firenze, pp. 11-39. 


\section{ANEXOS}

Tabela 3. Quadro sintético tomada de turno estudantes nível inicial e avançado.

\begin{tabular}{|c|c|c|}
\hline & NÍVEL INICIAL & NÍVEL AVANÇADO \\
\hline Sì & 247 & 111 \\
\hline Eh, ah, mh & 202 & 87 \\
\hline Forse & 60 & 41 \\
\hline Non so & 20 & 52 \\
\hline Penso che & 43 & 82 \\
\hline Possiamo & 40 & 56 \\
\hline Dobbiamo & 33 & 30 \\
\hline Facciamo & 10 & 27 \\
\hline Magari & 7 & 2 \\
\hline Bom & 5 & 0 \\
\hline Então & 2 & 0 \\
\hline Allora & 3 & 0 \\
\hline Ma & 12 & 16 \\
\hline Comunque & 3 & 0 \\
\hline TOTAL & 687 & 504 \\
\hline
\end{tabular}

Tabela 4. Quadro sintético fatismos estudantes nível inicial e avançado

\begin{tabular}{|c|c|c|}
\hline & NÍVEL INICIAL & NÍVEL AVANÇADO \\
\hline Dimmi & 21 & 0 \\
\hline Vedi & 9 & 0 \\
\hline Sai & 2 & 0 \\
\hline TOTAL & 32 & 0 \\
\hline
\end{tabular}

Tabela 5. Quadro sintético sinais de concordância falante estudantes nível inicial e avançado.

\begin{tabular}{|c|c|c|}
\hline & NÍVEL INICIAL & NÍVEL AVANÇADO \\
\hline No? & 4 & 6 \\
\hline Giusto? & 0 & 3 \\
\hline TOTAL & 4 & 9 \\
\hline
\end{tabular}


Tabela 6. Quadro sintético sinais de concordância interlocutor estudantes nível inicial e avançado.

\begin{tabular}{|c|c|c|}
\hline & NÍVEL INICIAL & NÍVEL AVANÇADO \\
\hline Sì & 247 & 111 \\
\hline Sì sì & 97 & 58 \\
\hline Sì dai! & 7 & 0 \\
\hline Sì bravo & 0 & 8 \\
\hline Sì certo & 3 & 9 \\
\hline Sì è vero & 1 & 11 \\
\hline Sì è una buona idea & 0 & 6 \\
\hline Va bene & 0 & 1 \\
\hline Esatto & 0 & 206 \\
\hline TOTAL & 355 & \\
\hline
\end{tabular}

Tabela 7. Quadro sintético sinais de confirmação de atenção e back-channels estudantes nível inicial e avançado.

\begin{tabular}{|c|c|c|}
\hline & NÍVEL INICIAL & NÍVEL AVANÇADO \\
\hline Sì & 29 & 27 \\
\hline Mhm Mhm & 20 & 18 \\
\hline TOTAL & 49 & 45 \\
\hline
\end{tabular}

Tabela 8. Quadro sintético indicadores de reformulação estudantes nível inicial e avançado.

\begin{tabular}{|c|c|c|}
\hline & NÍVEL INICIAL & NÍVEL AVANÇADO \\
\hline Come si dice? & 16 & 5 \\
\hline Come posso dire? & 14 & 3 \\
\hline Non so & 15 & 4 \\
\hline TOTAL & 45 & 12 \\
\hline
\end{tabular}

Tabela 9. Quadro sintético demarcativos com função argumentativa, consecutiva e adicional estudantes nível inicial e avançado.

\begin{tabular}{|c|c|c|}
\hline & NÍVEL INICIAL & NÍVEL AVANÇADO \\
\hline No però & 1 & 5 \\
\hline Sì però & 1 & 3 \\
\hline
\end{tabular}




\begin{tabular}{|c|c|c|}
\hline Ma & 1 & 2 \\
\hline No perché & 1 & 2 \\
\hline Então & 1 & 0 \\
\hline Comunque & 1 & 0 \\
\hline TOTAL & 6 & 12 \\
\hline
\end{tabular}

Recebido: 26/03/2018

Aceito: 19/09/2018 